\title{
Catalytic Synthesis of Terminal Epoxides via Methylene Transfer to Aldehydes
}

Corey-Chaykovsky reaction

sulfide catalysis

epoxidation

methylene transfer

aldehydes

Plausible catalytic cycle:<smiles>CCCCC1CO1</smiles><smiles>[O-]C(C[SH]1CCCC1)c1ccccc1</smiles><smiles>CCCCC(C)Cc1ccccc1</smiles>

\section{(20 mol\%)}

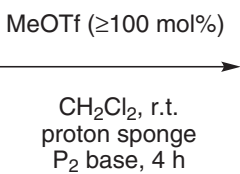

$\mathrm{P}_{2}$ base, $4 \mathrm{~h}$<smiles>[2H]C=O</smiles>

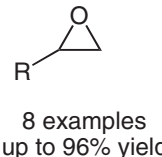

up to $96 \%$ yield
Significance: Connon's group reports a highly efficient protocol for the synthesis of terminal epoxides via a catalytic methylene transfer reaction to aldehydes. The use of a simple sulfide catalyst in combination with stoichiometric amounts of MeOTf and the $\mathrm{P}_{2}$ phosphazene base resulted in the in situ generation of a reactive sulfur ylide. Subsequent methylene transfer to aromatic as well as $\alpha$-branched aliphatic aldehydes furnished the desired epoxides in high yields. With newly synthesized chiral sulfides the authors report a catalytic asymmetric version of their reaction as well, although only moderate enantioselectivities have been obtained so far.
Catalytic asymmetric version:

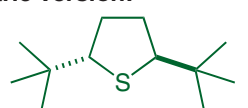

(20 mol\%)

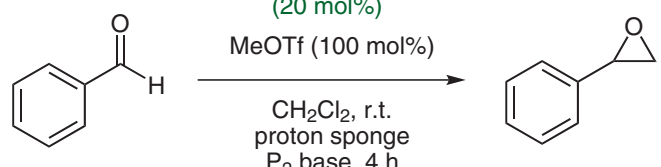

$70 \%$ yield er $=71.5: 28.5$
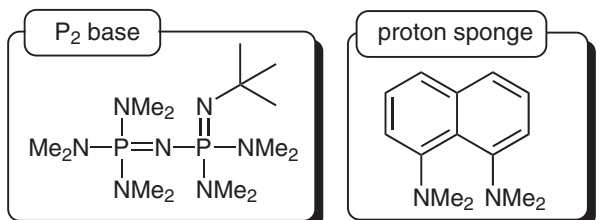

Comment: The Corey-Chaykovsky epoxidation is a popular approach for the synthesis of (enantiomerically enriched) epoxides. However, in this respect the methylene transfer to aldehydes suffered from low catalyst activity so far. By the careful choice of reagents based on the investigation of the individual steps of the proposed catalytic cycle, the authors developed a highly efficient protocol for this reaction. Additionally they underlined the immense potential of their method by the development of a catalytic asymmetric version. Although enantioselectivities are only moderate so far, further reports on advanced methods can be expected in due course.

SYNFACTS Contributors: Benjamin List, Steffen Mülle Dol: 10.1055/s-0029-1219416; Reg-No.: B01010SF 